\title{
Aromaticity introduced by antiferromagnetic ligand mediated metal-metal interactions. Insights from the induced magnetic response in $[\mathrm{Cu}-6(\mathrm{dmPz})(6)(\mathrm{OH})(6)]$
}

Molina, V.

2017-06-01

Molina , V , Rauhalahti , M , Hurtado , J , Fliegl , H , Sundholm , D \& Munoz-Castro , A 2017

, ' Aromaticity introduced by antiferromagnetic ligand mediated metal-metal interactions. Insights from the induced magnetic response in [Cu-6(dmPz)(6)(OH)(6)] ', Inorganic Chemistry Frontiers, vol. 4 , no. 6 , pp. 986-993 . https://doi.org/10.1039/c7qi00023e

http://hdl.handle.net/10138/307922

https://doi.org/10.1039/c7qi00023e

unspecified

acceptedVersion

Downloaded from Helda, University of Helsinki institutional repository.

This is an electronic reprint of the original article.

This reprint may differ from the original in pagination and typographic detail.

Please cite the original version. 


\section{Journal Name}

\section{ARTICLE}

Received 00th January 20xx, Accepted 00th January 20xx

DOI: $10.1039 / \times 0 \times x 00000 x$

www.rsc.org/

\section{Aromaticity Introduced by Antiferromagnetic Ligand Mediated Metal-Metal Interactions. Insights from the Induced Magnetic Response in $\left[\mathrm{Cu}_{6}(\mathrm{dmPz})_{6}(\mathrm{OH})_{6}\right]$}

\begin{abstract}
V. Molina ${ }^{a, b}$, M. Rauhalahtic ${ }^{c}$ J. Hurtado ${ }^{d}$, H. Fliegl ${ }^{e}$, D. Sundholm ${ }^{c}$ and A. Muñoz-Castro ${ }^{a, f^{*}}$
[trans- $\mathrm{Cu}(\mu-\mathrm{OH})(\mu-\mathrm{dmpz})]_{6}(\mathbf{1})$, exhibits six $\mathrm{Cu}(\mathrm{II})$ centers effectively coupled through an ligand mediated mechanism leading to a diamagnetic ground state for a wide temperature interval. Here we investigate further magneto-structural correlations standing on the possible free electron precession along such a copper-based ring-like nanocoil mediated by the bridging ligands. We find that in $\mathbf{1}$, the mediated antiferromagnetic coupling leads to the characteristic that reminisce the aromatic ring behavior through evaluation of both induced currents and shielding cones from relativistic density functional theory level. According to our calculations of gauge including magnetically induced current densities and the induced magnetic field, a sizable ring current strength susceptibility is obtained for the cyclic $\mathrm{Cu}-\mathrm{N}-\mathrm{N}-\mathrm{Cu}$ and $\mathrm{Cu}-\mathrm{O}-\mathrm{Cu}$ pathways allowing a magnetic exchange between the copper centers. Our study suggests that $\left[\mathrm{Cu}_{6}(\mathrm{dmPz})_{6}(\mathrm{OH})_{6}\right]$ consisting of an aromatic ring structure displays aromaticity and superexchange along the $\mathrm{Cu}-\mathrm{O}-\mathrm{Cu}$ and $\mathrm{Cu}-\mathrm{N}-\mathrm{N}-\mathrm{Cu}$ backbones, which accounts for the $80 \%$ and $20 \%$ of the overall ring current strength susceptibility, respectively. This unravels the presence of particular aromatic rings characteristics in coordination compounds without a direct metal-metal bond, where several formally paramagnetic centers are antiferromagnetically-coupled through supporting ligands. We envisage that our findings can be extended to other examples depicting ligand-mediated interaction between metal centers.
\end{abstract}

\section{Introduction}

Polynuclear metal coordination compounds represent an interesting class of molecules in the fields of inorganic chemistry and material science due to their intriguing structures, high connectivity and large stability. ${ }^{1-6}$ Such systems exhibit tailorable magnetic and catalytic properties, which are relevant for a wide range of technological applications. ${ }^{6-13}$ Since the early days of molecular magnetism, small complexes involving copper(II) ions have been the topic of intense research efforts by both synthetic and theoretical

${ }^{a}$ Grupo de Química Inorgánica y Materiales Moleculares, Universidad Autonoma de Chile, El Llano Subercaseaux 2801, Santiago, Chile.

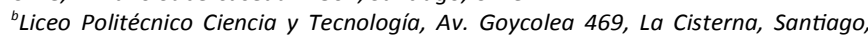
Chile.Email: alvaro.munoz@uautonoma.cl

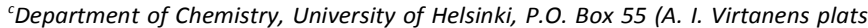
1), FIN-00014, Finland.

${ }^{d}$ Departamento de Química, Universidad de los Andes, Carrera 1 No. 18A-12, 111711, Bogotá, Colombia.

${ }^{e}$ Centre for Theoretical and Computational Chemistry (CTCC), Department of Chemistry, P. O. Box 1033 Blindern, University of Oslo, Oslo, Norway.

${ }^{f}$ Doctorado en Fisicoquímica Molecular, Universidad Andres Bello, Av. Republica 275, Santiago, Chile.

† Footnotes relating to the title and/or authors should appear here.

Electronic Supplementary Information (ESI) available: Optimized coordinates for [trans- $\mathrm{Cu}(\mu-\mathrm{OH})(\mu-\mathrm{dmpz})]_{6}$. See DOI: 10.1039/x0xx00000x chemists, focusing into the antiferromagnetic exchange coupling between the paramagnetic $d^{9}-\mathrm{Cu}(\mathrm{II})$ ions. ${ }^{14-20}$ These joint efforts have led to novel classes of related molecules that function as valuable model systems to test new theories for understanding the role of the ligands connecting the metal centers. $^{21-25}$

The coordination chemistry of $\mathrm{Cu}(\mathrm{II})$ is a very active research field where the studies comprise synthesis of new polynuclear complexes by taking advantage of the structural versatility provided by $\mathrm{N}$-donor ligands. The use of five-membered heterocyclic rings has shown to be effective in the synthesis of discrete metal-organic assemblies with variable nuclearities and sizes. ${ }^{26-32}$ Metal-organic structures involving six, eight, and larger number of copper atoms have been characterized, given by $[\text { trans- } \mathrm{Cu}(\mu-\mathrm{OH})(\mu-\mathrm{dmpz})]_{\mathrm{n}}(\mathrm{n}=6,8)^{33-35}$ and $[\mathrm{cis}-\mathrm{Cu}(\mu-\mathrm{OH})(\mu-$ $p z)]_{n}(n=6,8,9,10$, etc. $){ }^{36} \quad(p z=$ pyrazole; $d m p z=3,5-$ dimethylpyrazole). Moreover, complexes with high nuclearities have been also observed, leading to a unique and novel class of anion-sequestering agents (nanojars). ${ }^{37-39}$

The $[\text { trans- } \mathrm{Cu}(\mu-\mathrm{OH})(\mu-\mathrm{dmpz})]_{6}$ complex (1) involves six formally paramagnetic $\mathrm{Cu}(\mathrm{II})$ centers in a cyclic structure. However, a strong antiferromagnetic ground spin state $(S=0)$ has been experimentally characterized via temperature 


\section{ARTICLE}

dependent magnetic susceptibility meassurements, ${ }^{34}$ which is well separated from other spin states, ensuring the diamagnetic state. $^{34}$ This is also found for a related fluoromethyl derivative by Mohamed and coworkers. ${ }^{40}$

Owing to the long $\mathrm{Cu}-\mathrm{Cu}$ distances in $\mathbf{1}$ (3.181 $\AA$ ), no direct orbital overlap within $\mathrm{Cu}_{6}$ backbone is expected. Thus, the strong antiferromagnetic coupling observed between the paramagnetic centers is mediated by the ligands

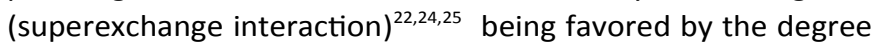
of covalency, ${ }^{41}$ which ensures the characterized overall singlet spin ground state. Hence, $[\text { trans- } \mathrm{Cu}(\mu-\mathrm{OH})(\mu-\mathrm{dmpz})]_{6}$ complex appears as a suitable system for exploring the consequences of an effective ligand mediated antiferromagnetic coupling of cyclic metal-ligand structures.

The aim of this work is to investigate whether the ligand assisted $\mathrm{Cu}-\mathrm{Cu}$ interactions in $\mathbf{1}$ can lead to an antiferromagnetic network favoring a free electron precession in such circular nanocoil when exposing the molecule to an external magnetic field. Since magnetically induced ring currents are typical for aromatic molecular rings, ${ }^{42,43}$ an eventual ring current relates the antiferromagnetic coupling and aromaticity, which reveals a novel property for cyclic molecular systems with ligand-mediated metal-metal interactions between paramagnetic centers. Thus, extending knowledge in magneto-structural relationships in the magnetochemistry field. The investigated structure exhibits two bonding backbones involving the hydroxyl- and pyrazole ligands, respectively, which are known to mediate the antiferromagnetic coupling between the $\mathrm{Cu}$ atoms and eventually also sustain magnetically induced ring currents.

Herein, we elucidate the magnetic behavior of the diamagnetic 1 in the presence of an external magnetic field. Two complementary approaches have been employed namely, calculations of the current density using the gauge including magnetically induced current (GIMIC) method ${ }^{43-45}$ and calculations of the magnetic response function in discrete points around the entire molecule. The current density calculations provide quantitative values for the current strength passing chosen planes in the molecule and it can also be used for visualizing the magnetically induced current density, which in turn give rise to the induced magnetic field that is obtained using the second approach.
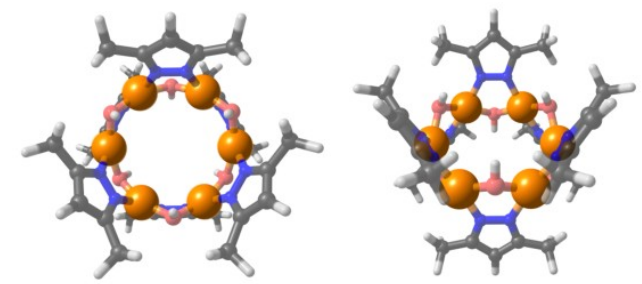

Figure 1. Two views of the optimized structure for $\left[\mathrm{Cu}_{6}(\mathrm{dmPz})_{6}(\mathrm{OH})_{6}\right]$

\section{Computational Details}

Relativistic density functional theory (DFT) calculations ${ }^{46}$ were carried out using the ADF code ${ }^{47}$, incorporating scalar
Journal Name

relativistic effects via the one and two-component ZORA Hamiltonian ${ }^{48}$. We employed all electron triple- $\zeta$ Slater basis sets augmented with two polarization functions (STO-TZ2P) for valence electrons, and the non-local Becke-Perdew (BP86) functional within the generalized gradient approximation (GGA). ${ }^{49-51}$ Geometry optimizations were performed without any symmetry constraints, via the analytical energy gradient method implemented by Versluis and Ziegler ${ }^{52}$. In order to consider long-range interactions, Grimme's dispersion correction was added for both geometry optimizations and energy decomposition analysis. ${ }^{53}$

The nuclear magnetic shielding constants and nucleusindependent shielding tensors were calculated with the NMR module of ADF at the DFT BP86 level using the using the STOTZ2P basis set employing gauge-including atomic orbitals (GIAO)..$^{54-57}$

The magnetically induced current density susceptibilities were calculated using the gauge including magnetically induced current (GIMIC) method. ${ }^{43-45}$ In the GIMIC calculations, the input information comprises basis set data, the unperturbed and first order magnetically perturbed atomic orbital density matrices obtained from the Kohn-Sham and NMR calculations, respectively. The density matrices were obtained at the BP86/ def2-TZVP level in combination with the resolution of the identity (RI) or density fitting approximation using Turbomole version 7.0..$^{58-62}$

A faster basis set convergence is achieved by using perturbation dependent basis sets for the calculation of the magnetically induced current density. Thus, current densities calculated with triple- $\zeta$ basis sets are close to the basis-set limit. Magnetically induced current density studies including an integration analysis of the current flow have proven to be a very reliable means for aromaticity assignments according to the magnetic criterion, ${ }^{43,45}$ in particular when investigating complex multiring molecules. ${ }^{45,63}$

Aromaticity has been suggested to be multidimensional i.e., various means to measure it provides different degree of aromaticity. ${ }^{42,64-67}$ However, in more recent studies the multidimensionality of the aromaticity concept has been questioned, ${ }^{68,69}$ because for multiring systems aromaticity is a global property involving several rings along different pathways. ${ }^{43}$ Many employed aromaticity criteria yield the degree of aromaticity of individual molecular rings, $^{70-72}$ because they are not easily applicable to molecules consisting of many annelated rings. ${ }^{63}$ Calculations of magnetically induced current strengths give a more accurate picture of the electron delocalization, since they show how and to what extent electrons move around the molecular rings when the molecule is exposed to an external magnetic field, ${ }^{44}$ which is a relevant characteristic of aromatic species. ${ }^{42,66,73-75}$

\section{Results and Discussion}

The molecular structure of $[\text { trans }-\mathrm{Cu}(\mu-\mathrm{OH})(\mu-\mathrm{dmpz})]_{6}$ is shown in Figure 1. It has $D_{3 d}$ symmetry with the $\mathrm{dmpz}^{-}$and $\mathrm{OH}^{-}$ligands distributed in a trans arrangement, involving six formally $\mathrm{Cu}$ (II) centers. The calculated structure agrees with the experimental one, ${ }^{34}$ suggesting that the molecular properties are well 
Journal Name

accounted at the employed present level of theory. The Cu-Cu distances are $3.190 \AA$ as compared with the experimental distance of $3.181 \AA$ obtained in X-ray measurements. The calculated $\mathrm{Cu}-\mathrm{N}$ and $\mathrm{Cu}-\mathrm{O}$ distances are 1.952 and $1.948 \AA$, and the corresponding experimental values are 1.952 and 1.934 A. ${ }^{34}$

A molar magnetic susceptibility $\left(\chi_{\mathrm{m}} T\right)$ of 2.25 emu mol ${ }^{-1} \mathrm{~K}$ is expected for six magnetically isolated copper(II) centers ${ }^{34,40}$. In contrast, the smaller $\chi_{\mathrm{m}} T$ product value experimentally measured of 0.5 emu mol ${ }^{-1} \mathrm{~K}$ at room temperature, and close to zero at temperatures below $50 \mathrm{~K}$, indicates that there is a strong antiferromagnetic coupling between the $\mathrm{Cu}$ centers ${ }^{34}$ ensuring a diamagnetic $S=0$ ground state. From the brokensymmetry (BS) procedure developed by Noodleman ${ }^{76-78}$ a BS solution of the singlet ground state is obtained where each $\mathrm{Cu}$ center carries a \pm 0.39 spin density in an alternate fashion (supporting information), accounting for the singlet state. A comparison between both restricted and BS states related to the overall diamagnetic ground state reveal that the latter is slightly favoured by $4.7 \mathrm{kcal} / \mathrm{mol}$, suggesting that such solutions are comparable in terms of stability.

In this sense, the magnetic exchange between the copper ions can be transmitted through the $\mathrm{Cu}-\mathrm{N}-\mathrm{N}-\mathrm{Cu}$ and $\mathrm{Cu}-\mathrm{O}-\mathrm{Cu}$ moieties with similar or different contribution to the overall antiferromagnetic coupling. In order to unravel the preferred magnetic coupling pathway, we evaluate the interaction energy of each ligand in $\mathbf{1}$. The analysis of the interaction between $\mathrm{Cu}$ and the pyrazol or the hydroxyl group leading to the formation of $\mathbf{1}$ were carried for both [dmpz ] $\left[\mathrm{Cu}_{6}(\mathrm{dmpz})_{5}(\mathrm{OH})_{6}\right]^{+}$and $\left[\mathrm{OH}^{-}\right]-\left[\mathrm{Cu}_{6}(\mathrm{dmpz})_{6}(\mathrm{OH})_{5}\right]^{+}$fragments, owing to their favorable oxidation state as isolated species. The charge distribution analysis of $\mathbf{1}$ based on Hirshfeld charges exhibits that the dmpz and $\mathrm{OH}^{-}$ligands in the restricted state have charges of -0.49 and -0.53 a.u., respectively, and of -0.51 and -0.55 a.u. in the brokensymmetry state, as compared with their formal charge of -1 as isolated species. Thus the charge distribution in both solutions for the singlet ground state is similar. Owing that the detailed analysis of the bonding interaction is not available for brokensymmetry states, we based the following findings in the restricted state unless stated otherwise.

The obtained interaction energies $\left(\Delta E_{\text {int }}\right)$ for the bridging ligands are -163.0 and $-169.5 \mathrm{kcal} \mathrm{mol}^{-1}$, respectively indicating equal energy contributions from the $\mathrm{Cu}-\mathrm{OH}-\mathrm{Cu}$ and $\mathrm{Cu}-\mathrm{N}-\mathrm{N}-\mathrm{Cu}$ moieties to the formation of the $\mathrm{Cu}_{6}$ ring. A large metal-ligand orbital overlap connecting the six copper ions along the backbone is obtained, showing its important role for the stability of $\mathbf{1}$ and for the effective ligand-mediated spin coupling mechanism. ${ }^{41}$

To explore the nature of this interaction, we performed the energy decomposition analysis (EDA) within the Morokuma-Ziegler scheme ${ }^{79-81}$. This allows describing $\Delta E_{\text {int }}$ in terms of different chemically meaningful contributing terms (see Table 1):

$$
\Delta E_{\text {int }}=\Delta E_{\text {pauli }}+\Delta E_{\text {orb }}+\Delta E_{\text {elstat }}+\Delta E_{\text {disp }}
$$

The stabilizing $\Delta E_{\text {elstat }}$ term refers to the electrostatic character of the interaction, which is obtained by considering each defined fragment (e.g., A and B) in its unperturbed (frozen) electron density as isolated species $\left(\Psi_{\mathrm{A}} \Psi_{\mathrm{B}}\right)$. The repulsive $\Delta E_{\text {Paul }}$ quantity accounts for the four-electron two-orbital interactions between occupied orbitals, which is calculated from the energy change due to the antisymmetrization and renormalization of the overlapping fragment densities $\left(\Psi_{0}=\right.$ $\left.N \hat{A}\left\{\Psi_{A} \Psi_{B}\right\}\right)$. The stabilizing $\Delta E_{\text {orb }}$ term is obtained when the densities of the constituent fragments relax into the final molecular orbitals $\left(\Psi_{\mathrm{AB}}\right)$ accounting for the covalent character of the interaction. In addition, the pairwise dispersion correction $^{53}$ (DFT-D3) allows us to evaluate the dispersion interaction $\left(\Delta E_{\text {disp }}\right)$ related to London forces. To overcome basis set superposition errors (BSSE), the counterpoise correction was employed. ${ }^{82}$

The ratio between the stabilizing quantities reported in Table 1, namely, $\Delta E_{\text {orb }}, \Delta E_{\text {elstat }}$ and $\Delta E_{\text {disp, }}$ yields the overall electrostatic or covalent character of the metal-ligand interaction. For both ligands, the stabilizing nature of $\Delta E_{\text {int }}$ is mainly dominated by the $\Delta E_{\text {elstat }}$ term ( $\left.69 \%\right)$, which is the main contribution to the electrostatic character of the chemical bonding when forming 1 with formally $\mathrm{Cu}(\mathrm{II})$ centers and anionic ligands. $\Delta E_{\text {elstat }}$ are -284.3 and $-278.5 \mathrm{kcal} \mathrm{mol}^{-1}$, for the $\mathrm{dmpz}$ and $\mathrm{OH}^{-}$ligands, suggesting a slightly more favorable electrostatic interaction in the former. The $\Delta E_{\text {orb }}$ terms, which are -115.7 and $-125.8 \mathrm{kcal} \mathrm{mol}^{-1}$, respectively, indicate that the charge-transfer interaction is also contributing significantly $(\sim 30 \%)$ to the overall electrostatic interaction of the $\mathrm{Cu}(\mathrm{II})$ ligand bonding. The bond formation in the cyclic structure results from the overlap between $\mathrm{Cu} 3 d$ orbitals and appropriate ligand orbitals, which in turn leads to the effective ligand-mediated spin coupling mechanism of the observed singlet spin ground state. ${ }^{34}$

The different bonding contributions to the $\Delta E_{\text {orb }}$ term can be further described through the Energy Decomposition Analysis with Natural Orbitals for Chemical Valence ${ }^{83-85}$ (EDA-NOCV).

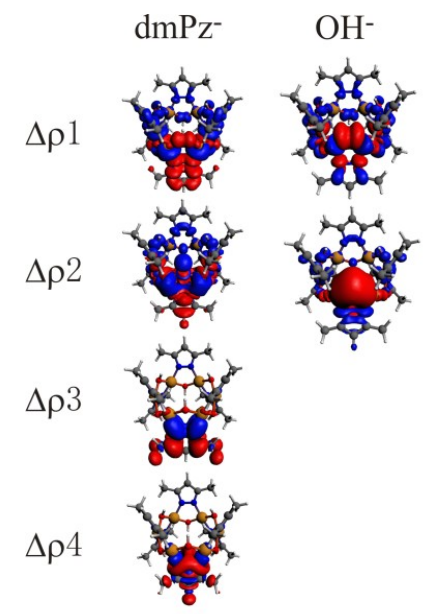

Figure 2. Deformation densities from the NOCV-EDA analysis. See text and Table 1.

When analyzing the major contributions to the orbital interaction term, as provided by the deformation densities of the NOCV analysis in Figure 2 and Table 1, it turns out that the bond formation along the structural backbones of $\mathbf{1}$ is of $\sigma$ character. The bonding interaction is accounted for by two main contributions to the deformation density, namely $\Delta \rho_{1}$ and 


\section{ARTICLE}

$\Delta \rho_{2}$, depicting the $\mathrm{Cu} \leftarrow \mathrm{dmpz}^{-}$and $\mathrm{Cu} \leftarrow \mathrm{OH}^{-}$charge transfers. The two major orbital interactions are sizable and contribute approximately $71 \%$ and $88 \%$ to the $\Delta E_{\text {orb }}$ term, compromising a charge estimation $\left(\Delta q_{n}\right)$ of 0.80 and 0.90 a.u., respectively. The $\pi$-donation in $\mathrm{dmpz}^{-}$covering the $\mathrm{Cu} \rightarrow \mathrm{dmpz}^{-}$back bonding is given by $\Delta \rho_{3}$ and $\Delta \rho_{4}$, which contribute roughly $12 \%$ to the density difference (with a $\Delta \mathrm{q}_{3}=0.28$ and $\Delta \mathrm{q}_{4}=0.18$ ). The $\sigma$ contributions to the deformation densities $\left(\Delta \rho_{1}\right.$ and $\left.\Delta \rho_{2}\right)$ obtained in both fragmentation schemes suggest that the bonding is delocalized over the structure involving both ligands.

Table 1. Energy decomposition analysis for ligand interaction, and the corresponding energy and charge transfer from each relevant density deformation channels from NOCV-EDA $\left(\Delta \mathrm{E}_{\mathrm{n}}{ }^{\text {rbb }}\right.$ and $\left.\Delta \mathrm{q}_{\mathrm{n}}\right)$. The values for $\Delta \mathrm{E}$ are given in $\mathrm{kcal} \cdot \mathrm{mol}^{-1}$ and $\Delta \mathrm{q}$ in a.u..

\begin{tabular}{|c|c|c|c|c|}
\hline & $\mathrm{dmpz}$ & & $\mathrm{OH}^{-}$ & \\
\hline$\Delta \mathrm{E}_{\text {Pauli }}$ & 245.6 & & 238.5 & \\
\hline$\Delta \mathrm{E}_{\text {orb }}$ & $\begin{array}{c}-115.7 \\
(28.3 \%) \\
\end{array}$ & & $\begin{array}{c}-125.8 \\
(30.8 \%) \\
\end{array}$ & \\
\hline$\Delta \mathrm{E}_{\text {Elstat }}$ & $\begin{array}{c}-284.3 \\
(69.6 \%) \\
\end{array}$ & & $\begin{array}{c}-278.5 \\
(68.3 \%) \\
\end{array}$ & \\
\hline$\Delta \mathrm{E}_{\text {Disp }}$ & $\begin{array}{c}-8.6 \\
(2.1 \%)\end{array}$ & & $\begin{array}{c}-3.7 \\
(0.9 \%)\end{array}$ & \\
\hline \multirow[t]{2}{*}{$\Delta \mathrm{E}_{\text {lnt }}$} & -163.0 & & -169.5 & \\
\hline & $\Delta \mathrm{E}_{\mathrm{n}}^{\text {orb }}$ & $\Delta q_{n}$ & $\Delta \mathrm{E}_{\mathrm{n}}^{\text {orb }}$ & $\Delta \mathrm{q}_{\mathrm{n}}$ \\
\hline$\Delta \rho_{1}$ & $\begin{array}{c}-45.9 \\
(39.7 \%)\end{array}$ & 0.80 & $\begin{array}{c}-70.0 \\
(55.7 \%)\end{array}$ & 0.91 \\
\hline$\Delta \rho_{2}$ & $\begin{array}{c}-36.7 \\
(31.7 \%)\end{array}$ & 0.69 & $\begin{array}{c}-41.1 \\
(32.7 \%)\end{array}$ & 0.57 \\
\hline$\Delta \rho_{3}$ & $\begin{array}{c}-6.1 \\
(5.3 \%) \\
\end{array}$ & 0.28 & & \\
\hline$\Delta \rho_{4}$ & $\begin{array}{c}-6.0 \\
(5.2 \%)\end{array}$ & 0.18 & & \\
\hline
\end{tabular}

A comparison of the calculated values for $\Delta E_{\text {orb, }}$ shows that similar values are obtained for $\mathrm{OH}^{-}$and $\mathrm{dmpz}^{-}$, where $\mathrm{OH}^{-}$most likely forms a more favorable overlap than $\mathrm{dmpz}^{-}$. Both ligands offer a favorable overlap that connects the copper ions and thereby ensuring the characterized spin ground state, with a slightly larger contribution from $\mathrm{OH}^{-}$. Thus, we obtain three different delocalized bonding situations supporting the $\mathrm{Cu}_{6}$ ligand-mediated antiferromagnetic coupling in the overall diamagnetic structure of 1 . i) The magnetic coupling follows the $(\mathrm{Cu}-\mathrm{N}-\mathrm{N}-)_{6}$ backbone involving all the copper ions and the six dmpz ligands in the trans arrangement. ii) Analogously, the ( $\mathrm{Cu}-\mathrm{O}-)_{6}$ bonds of the $\mathrm{OH}^{-}$groups couple the spins of the $\mathrm{Cu}$ atoms, or, iii) a combination of a coupling via both backbones.

\section{Journal Name}

Figure 3. Two views of the electron density involving the contribution from $\mathrm{Cu} 3 d$-orbitals (isosurface value $=0.03$ a.u.).

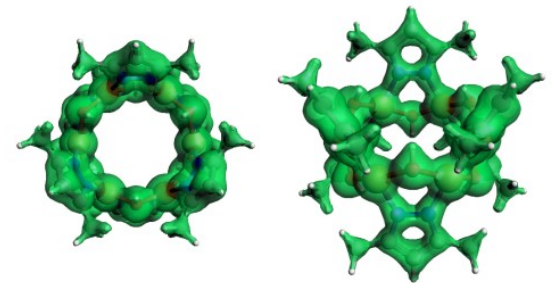

See text.

To evaluate the magnetic coupling pathway between the six $\mathrm{Cu}$ atoms, we calculate the electron density for all molecular orbitals with significant contributions from the $3 d$ orbitals of the $\mathrm{Cu}$ atoms. Contributions from $4 s$ - and $4 p$-Cu orbitals were not observed. In this sense, we can determine the magnetic exchange pathway due to the metal-ligand overlap that leads to the singlet electronic state observed experimentally (vide infra). The electron density in Figure 3 shows that the $3 d$ orbitals of the $\mathrm{Cu}$ atoms are delocalized along both ( $\mathrm{Cu}-\mathrm{N}-\mathrm{N}-)_{6}$ and $(\mathrm{Cu}-\mathrm{O}-)_{6}$ backbone leading to an efficient antiferromagnetic coupling between the six copper centers. Thus, the diamagnetic ground state of $[$ trans- $\mathrm{Cu}(\mu-\mathrm{OH})(\mu-$ $\mathrm{dmpz})]_{6}$ is caused by the interaction between the $\mathrm{Cu}$ atoms and both ligands, which contribute in the same way to the $\mathrm{Cu}$ Cu interaction.

The aromatic character of organic molecules has been widely interpreted in terms of the ring current contribution to magnetic shielding constants. ${ }^{70,75,87-89}$ Application of an external magnetic field $\left(\boldsymbol{B}^{\text {ext }}\right)$ perpendicularly to a molecular ring leads to an induced field $\left(\boldsymbol{B}^{\text {ind }}\right)$ opposed to the external one, resulting in a shielding response at the center of the ring. In contrast, for antiaromatic molecules, such induced magnetic field enhances $\boldsymbol{B}^{\text {ext }}$ leading to deshielding inside the ring. Calculating $\boldsymbol{B}^{\text {ind }}$ or actually the shielding tensor $(\sigma)$ function ${ }^{57}$ in discrete points in space around the studied molecules provides an overall picture of the short-ranged and long-ranged anisotropy cones, which are useful for understanding the magnetic anisotropies introduced by functional groups or molecules. ${ }^{90-92}$

The shielding function due to the magnetically induced current density was calculated in selected planes in the molecule. The graphical representation of the magnetic response $\left(\boldsymbol{B}^{\text {ind }}\right)$ of the applied external magnetic field $\left(\boldsymbol{B}^{\text {ext }}\right)$ was obtained as $\boldsymbol{B}_{i}^{\text {ind }}=-\boldsymbol{\sigma}_{i j}$ $\boldsymbol{B}_{j}^{\text {ext }}$ by calculating the nucleus independent shielding tensor $\left(\sigma_{i j}\right)$. Magnetic response is often given in terms of the more familiar magnetic chemical shift tensor $\left(\delta_{i j}=-\sigma_{i j}\right)$. In the visualization of the induced magnetic field, the direction of the external magnetic field is chosen to be oriented along one of the Cartesian directions ( $i$ ) showing the induced magnetic field along in other Cartesian directions (j). Analyses of given components of the shielding tensor provide an overall picture of the shielding and deshielding regions in the molecule. 


\section{$\left[\mathrm{Cu}_{6}(\mathrm{OH})_{6}(\mathrm{dmpz})_{6}\right]$}

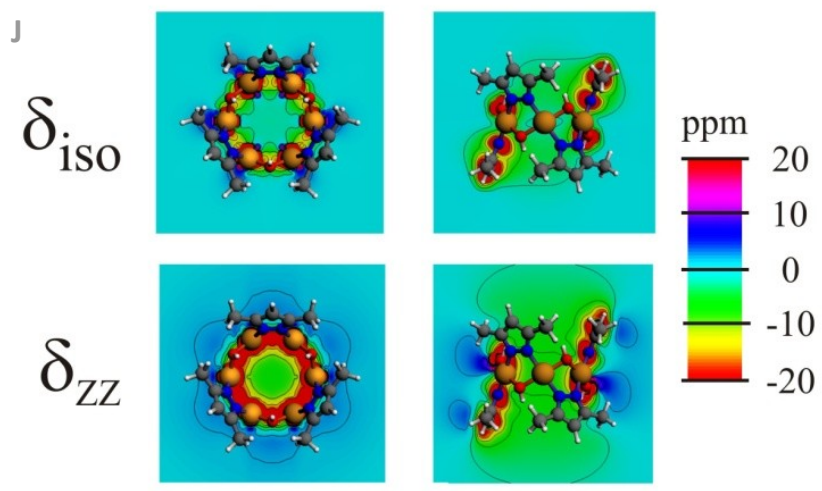

Figure 4. Shielding response under an applied field for 1. Isotropic and zz-components are given.

The isotropic response given by $\delta_{\text {iso }}$ (Figure 4), accounts for the experimental molecular tumbling of molecules in solution and gas-phase NMR experiments. For the restricted case (see above) the calculated shielding function exhibits a slight overlap of the induced shielding cones between the fivemembered aromatic rings ( $\mathrm{dmpz}^{-}$) towards the center of the structure. The isotropic contribution to the magnetic chemical shift in the center of the $\delta_{\text {iso }} \mathrm{Cu}_{6}$ ring, which is also called $\operatorname{NICS}(0),{ }^{71,72,88,89}$ is $-2.20 \mathrm{ppm}$. NICS(0) is the average of the response at the origin of $\mathbf{1}$ for the three different orientations of the external magnetic field, The shielding function shown in Figure 5 reach its maximum of -4.05 ppm at about $2.6 \AA$ due to the shielding contributions originating from the pyrazole rings. For the broken-symmetry state, similar values are found denoting that a related response is obtained when the external field is applied with NICS(0)=-2.15 ppm and -4.09 ppm $2.6 \AA$ at from the center.

The $\delta_{z z}$ component of the magnetic chemical shift function (also called NICSzz) ${ }^{77,78}$ provides information about the magnetic response in the $z$ direction when the external magnetic field is applied in the same direction. Thus, assuming a simple ring-current picture, the $\delta_{z z}$ component is related to ring-current strength perpendicularly to the external magnetic field. ${ }^{70,94-96}$ The NICSzz function reveals an interesting longranged shielding region at the center of 1 . The $\operatorname{NICSzz}(0)$ value at the center of the $\mathrm{Cu}_{6}$ ring is $\delta_{z z}=-7.11 \mathrm{ppm}$. Along the $z$-axis, the value of $\delta_{z z}$ reaches its maximum at the center of the molecule and decreases to $-5.00 \mathrm{ppm}$ at about $4.5 \AA$, and -3.0 ppm at $7.5 \AA$, illustrating the long range behavior of the shielding cone. A complementary deshielding region can also be observed. Similarly, for the broken-symmetry state the $\operatorname{NICSzz}(0)$ amounts to $-7.34 \mathrm{ppm}$, with a shielding function profile strongly related to the restricted solution.

Thus, $\mathbf{1}$ in both restricted and broken-symmetry solutions shows the typical characteristics for aromatic rings in metalligand complexes. The obtained magnetic behavior is due to the metal-ligand orbital overlap of the zig-zag Cu-N-N-Cu and $\mathrm{Cu}-\mathrm{O}-\mathrm{Cu}$ backbones that connect the copper ions. The magnetic response suggests that the $\left[\right.$ trans $\left.-\mathrm{Cu}_{6}(\mathrm{dmPz})_{6}(\mathrm{OH})_{6}\right]$ complex is an aromatic molecule where the superexchange interaction of the molecular rings gives rise to its aromatic character.

Moreover, the theoretical evaluation of the $\left[\right.$ cis- $\left.-\mathrm{Cu}_{6}(\mathrm{Pz})_{6}(\mathrm{OH})_{6}\right]$ counterpart, involving unsubstituted pyrazole rings, also
ARTICLE

suggest a singlet spin ground state mediated by the ligands. Similarly to $\left[\right.$ trans $\left.-\mathrm{Cu}_{6}(\mathrm{dmPz})_{6}(\mathrm{OH})_{6}\right]$, a shielding response at the center of the structure $(\operatorname{NICSzz}(0)=-3.37)$ is obtained when a magnetic field is perpendicularly applied in relation to the $\mathrm{Cu}_{6}$ plane (supporting information). This support that the ligand-mediated $\mathrm{Cu}-\mathrm{Cu}$ interactions induces an aromatic behavior to the overall structure.

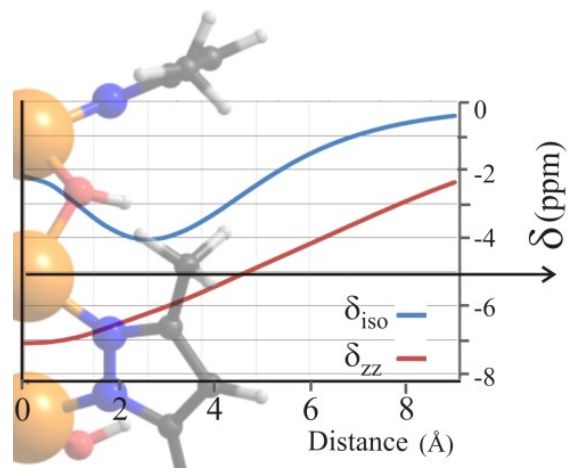

Figure 5. Shielding response profile along the z-axis. Isotropic and $z z$-components are given.

In order to evaluate an eventual electron precession along the ligand-mediated metal-metal interaction, which is typical for aromatic molecules, ${ }^{74,75}$ we calculated the current density induced by an external magnetic field (Figure 6) for the restricted case. Owing to the ring shape of 1 , the external field was oriented perpendicularly to the plane defined by the $\mathrm{Cu}_{6}$ ring. Calculations of the current density using the GIMIC method combined with a numerical integration analysis of the ring-current strengths show that $\mathbf{1}$ sustains indeed a net diatropic ring current whose current-strength susceptibility is $9.9 \mathrm{nA} / \mathrm{T}$. For comparison, the integrated ring-current strength susceptibility for benzene calculated at the same level of theory is $11.7 \mathrm{nA} / \mathrm{T} .{ }^{86}$ Thus, the molecular ring of $\mathbf{1}$ involving the six $\mathrm{Cu}$ atoms can be considered aromatic according to the obtained diatropic value for the magnetically induced ring current strength.

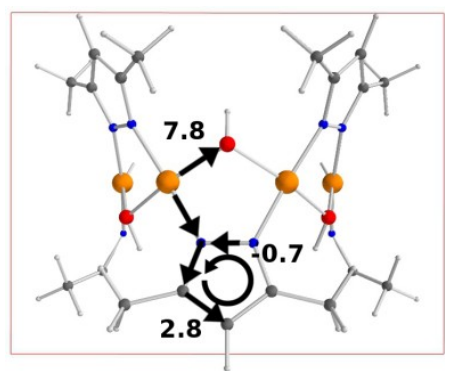

Figure 6. Calculated current pathways of Cu6. The numerical values are the integrated current strengths in $\mathrm{nA} / \mathrm{T}$ calculated along the respective current pathway. Black arrows indicate the direction of the current flow assuming that diatropic currents circle counterclockwise. Copper atoms are displayed in orange, oxygen in red and nitrogen in blue, carbon atoms in black, and hydrogen atoms in light grey.

The induced current route along the $(\mathrm{Cu}-\mathrm{N}-\mathrm{N}-)_{6}$ and $(\mathrm{Cu}-\mathrm{O}-)_{6}$ backbones (Figure 6), is reminiscent of the magnetic exchange 
ARTICLE

pathways obtained from the analysis of the molecular orbitals with significant contributions from $3 d$ orbitals of the $\mathrm{Cu}$ atoms. Thus, the magnetic exchange pathway and the electron current pathway are concordant. Bifurcation of the current was assessed by integrating the domains attributed to different pathways. The domains were chosen by visual inspection of the modulus of the ring current, as depicted in Figure 7. By comparing the strengths of the net ring current along the two backbones, one sees that the current splits at the $\mathrm{Cu}$ centers with $7.8 \mathrm{nA} / \mathrm{T}$ taking the $\mathrm{Cu}-\mathrm{O}-\mathrm{Cu}$ pathway and $2.1 \mathrm{nA} / \mathrm{T}$ is passing via the $\mathrm{Cu}-\mathrm{N}-\mathrm{N}-\mathrm{Cu}$ route. The fivemembered dmpz rings sustain a small local diamagnetic ring current of $0.7 \mathrm{nA} / \mathrm{T}$, manifesting as an integrated net current strength of $2.8 \mathrm{nA} / \mathrm{T}$ for the $\mathrm{dmpz}$ ring. There is no throughspace current between the $\mathrm{Cu}$ atoms, confirming the indirect $\mathrm{Cu}-\mathrm{Cu}$ orbital interaction. Hence, the $(\mathrm{Cu}-\mathrm{O}-)_{6}$ backbone sustaining $79 \%$ of the current strength is the preferred route for the magnetically induced current density accounting mainly for its aromatic character. About one fifth of the current strength passes along the (Cu-N-N-$)_{6}$ backbone.

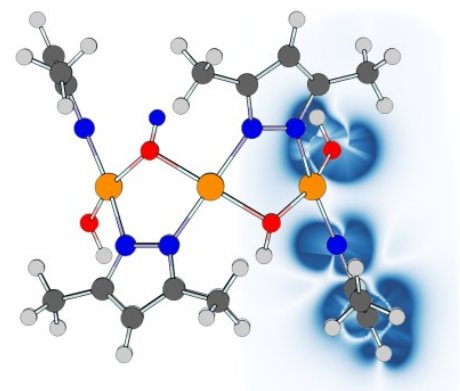

Figure 7. Modulus of the current density on a plane bisecting two copper atoms. Modulus of the current density was visualized with matplotlib using a cutoff value of $0.01 \mathrm{nA} / \mathrm{T}$, and the plot was overlayed on isometrically visualized Cu6 using GIMP.

\section{Conclusions}

The six paramagnetic $\mathrm{Cu}(\mathrm{II})$ centers forming a ring moiety with their ligands in $[\text { trans- } \mathrm{Cu}(\mu-\mathrm{OH})(\mu-\mathrm{dmpz})]_{6}$, are antiferromagnetically coupled resulting in a diamagnetic ground state, as observed from experimental magnetic susceptibility measurements. The coupling is mediated by the bridging dimethylpyrazolate and hydroxyl ligands, which contribute to the magnetic exchange pathway through an effective metal-ligand overlap. The bonding between $\mathrm{Cu}_{6}$ and the ligands is delocalized along the structure, which allows an electron precession when applying a magnetic field perpendicularly to the $\mathrm{Cu}_{6}$ containing ring. Our study shows that a sizable ring-current strength susceptibility is obtained for the cyclic Cu-ligand structure indicating that the ringshaped structure forms an aromatic ring. The $\mathrm{Cu}-\mathrm{O}-\mathrm{Cu}$ backbone is the preferred ring current pathway of the two possible routes accounting for the $80 \%$ of the overall induced current strength. $\left[\mathrm{Cu}_{6}(\mathrm{dmPz})_{6}(\mathrm{OH})_{6}\right]$ forms an aromatic ring structure sustaining magnetically induced current flows along
Journal Name

both the $\mathrm{Cu}-\mathrm{N}-\mathrm{N}-\mathrm{Cu}$ and the $\mathrm{Cu}-\mathrm{O}-\mathrm{Cu}$ backbones. Thus, the ligand-mediated spin coupling mechanism of cyclic metalorganic structures with magnetic exchange pathways such as in $\left[\mathrm{Cu}_{6}(\mathrm{dmPz})_{6}(\mathrm{OH})_{6}\right]$ can be related to the aromatic character of its molecular rings. We envisage that the mechanism can be extended to comprise also other cyclic diamagnetic structures with individual paramagnetic centers that are magnetically coupled through organic ligands.

\section{Acknowledgements}

The inclusion of Vannesa Molina is the result of the active outreach activities involving young researchers at high school level. The authors thank for the financial support for collaborative efforts given by FONDECYT 1140359, Project Millennium RC120001, and the Academy of Finland through projects 275845 and 289179 . DS thanks the Swedish Cultural Foundation in Finland and Magnus Ehrnrooth Foundation for financial support. Computational resources have been provided by CSC -- the Finnish IT Center for Science and by FONDECYT funds. HF thanks the Norwegian Research Council through the CoE Centre for Theoretical and Computational Chemistry (Grant No. 179568/V30 and 231571/F20) for support. This work has received support from the Norwegian Supercomputing Program (NOTUR) through a grant of computer time (Grant No. NN4654K). J.H. thanks to the Department of Chemistry and the School of Science of the Universidad de los Andes for the financial support. We thank to reviewers and Editor for they useful comments.

\section{References}

1

W.-C. Song, Q. Pan, P.-C. Song, Q. Zhao, Y.-F. Zeng, T.-L. Hu and X.-H. Bu, Chem. Commun., 2010, 46, 4890.

2

S. Kitagawa, R. Kitaura and S. Noro, Angew. Chemie Int. Ed., 2004, 43, 2334-2375.

3 D. Farrusseng, Metal-Organic Frameworks, VCH, Weinheim, Germany, 2011. D. Bradshaw, J. B. Claridge, E. J. Cussen, T. J. Prior and M. J. Rosseinsky, Acc. Chem. Res., 2005, 38, 273-282.

5 M. Oh, G. B. Carpenter and D. A. Sweigart, Acc. Chem. Res., 2004, 37, 1-11.

6 T. R. Cook, Y.-R. Zheng and P. J. Stang, Chem. Rev., 2013, 113, 734-777. L. Ma, D. J. Mihalcik and W. Lin, J. Am. Chem. Soc., 2009, 131, 4610-4612.

8 G. A. Senchyk, A. B. Lysenko, A. A. Babaryk, E. B. Rusanov, H. Krautscheid, P. Neves, A. A. Valente, I. S. Gonçalves, K. W. Krämer, S.-X. Liu, S. Decurtins and K. V. Domasevitch, Inorg. Chem., 2014, 53, 10112-10121. E. V Lider, E. V Peresypkina, A. I. Smolentsev, V. N. Elokhina, T. I. Yaroshenko, A. V Virovets, V. N. Ikorskii and L. G. Lavrenova, Polyhedron, 2007, 26, 1612-1618.

10 V. Venkatesh, P. Pachfule, R. Banerjee and S. Verma, Chem. - A Eur. J., 2014, 20, 12262-12268.

11 J.-B. Peng, Q.-C. Zhang, X.-J. Kong, Y.-Z. Zheng, Y.-P. Ren, L.- 
Journal Name

S. Long, R.-B. Huang, L.-S. Zheng and Z. Zheng, J. Am. Chem. Soc., 2012, 134, 3314-3317. P. J. Hagrman, D. Hagrman and J. Zubieta, Angew. Chemie Int. Ed., 1999, 38, 2638-2684.

13 R. Galassi, A. Burini and A. A. Mohamed, Eur. J. Inorg. Chem., 2012, 2012, 3257-3261. M. Trif, F. Troiani, D. Stepanenko and D. Loss, Phys. Rev. Lett., 2008, 101, 217201. T. Rojo, J. Darriet, J. M. Dance and D. Beltrán-Porter, Inorganica Chim. Acta, 1982, 64, L105-L107. B. Bleaney and K. D. Bowers, Proc. R. Soc. London Ser. 1952, 214, 451-465.

17 V. H. Crawford, H. W. Richardson, J. R. Wasson, D. J. Hodgson and W. E. Hatfield, Inorg. Chem., 1976, 15, 21072110.

B. M. Trost, S. A. Godleski and J. P. Genet, J. Am. Chem. Soc., 1978, 100, 3930-3931. P. R. Levstein and R. Calvo, Inorg. Chem., 1990, 29, 15811583. X. Rocquefelte, K. Schwarz and P. Blaha, Sci. Rep., 2012, 2. D. Gatteschi, O. Kahn and R. D. Willett, Magnetostructural Correlations in Exchange Coupled Systems, 1984.

O. Kahn, VCH Publ. Inc.(USA), 1993, 1993, 393. O. Kahn, P. Tola, J. Galy and H. Coudanne, J. Am. Chem. Soc., 1978, 100, 3931-3933.

R. Boca, Theoretical Foundations of Molecular Magnetism, Elsevier Science, 1st Editio., 1999.

J. Kanamori, J. Phys. Chem. Solids, 1959, 10, 87-98.

Y.-Y. Zhang, H. Zhao, E.-C. Yang, Z.-Y. Liu, Q. Shang and X.-J. Zhao, Dalt. Trans., 2015, 44, 5826-5836.

M. Su, M. Tomás-Gamasa, S. Serdjukow, P. Mayer and T. Carell, Chem. Commun., 2014, 50, 409-411.

S. Carlotto, M. Casarin, A. Lanza, F. Nestola, L. Pandolfo, C. Pettinari and R. Scatena, Cryst. Growth Des., 2015, 15, 5910-5918.

A. M. Lopez_Marzo, M. Guerrero, T. Calvet, M. Font-Bardia and J. Pons, Inorg. Chem. Commun., 2015, 55, 51-55.

L. Mathivathanan, M. Rivera-Carrillo and R. G. Raptis, Inorganica Chim. Acta, 2012, 391, 201-205. 2011, 50, 1014-1020.
G. A. Ardizzoia, M. A. Angaroni, G. La Monica, F. Cariati, S. Cenini, M. Moret and N. Masciocchi, Inorg. Chem., 1991, 30, 4347-4353.

W. Cañon-Mancisidor, C. J. Gómez-García, G. M. Espallargas, A. Vega, E. Spodine, D. Venegas-Yazigi and E. Coronado, Chem. Sci., 2014, 5, 324-332.

A. A. Mohamed, S. Ricci, A. Burini, R. Galassi, C. Santini, G. M. Chiarella, D. Y. Melgarejo and J. P. Fackler Jr, Inorg. Chem., 2010, 50, 1014-1020.

G. Mezei, P. Baran and R. G. Raptis, Angew. Chemie Int. Ed., 2004, 43, 574-577.

B. M. Ahmed, B. Calco and G. Mezei, Dalt. Trans., 2016, 45, 8327-8339.

G. Mezei, Chem. Commun., 2015, 51, 10341-10344.
I. R. Fernando, S. A. Surmann, A. A. Urech, A. M. Poulsen and G. Mezei, Chem. Commun., 2012, 48, 6860.

A. A. Mohamed, A. Burini, R. Galassi, D. Paglialunga, J.-R. Galán-Mascarós, K. R. Dunbar and J. P. Fackler, Inorg. Chem., 2007, 46, 2348-2349.

B. Feldscher, H. Theil, A. Stammler, H. Bögge and T. Glaser, Inorg. Chem., 2012, 51, 8652-8654.

R. Gershoni-Poranne and A. Stanger, Chem. Soc. Rev., 2015, 44, 6597-6615.

H. Fliegl, S. Taubert, O. Lehtonen and D. Sundholm, Phys. Chem. Chem. Phys., 2011, 13, 20500-18.

D. Sundholm, H. Fliegl and R. J. F. Berger, Wiley Interdiscip. Rev. Comput. Mol. Sci., 2016, 6, 639-678.

J. Jusélius, D. Sundholm, J. J. Gauss and J. Jusélius, J. Chem. Phys., 2004, 121, 3952-63.

K. G. Dyall and K. Fægri, Introduction to Relativistic Quantum Chemistry, Oxford University Press, New York, 2007.

E. van Lenthe, E.-J. J. Baerends and J. G. Snijders, J. Chem. Phys., 1994, 101, 9783.

A. D. Becke, Phys. Rev. A, 1988, 38, 3098-3100.

J. P. Perdew, Phys. Rev. B, 1986, 33, 8822.

S. H. Vosko, L. Wilk and M. Nusair, Can. J. Phys., 1980, 58, 1200-1211.

L. Versluis and T. Ziegler, J. Chem. Phys., 1988, 88, 322328.

S. Grimme, Wiley Interdiscip. Rev. Comput. Mol. Sci., 2011, 1, 211-228.

K. Wolinski, J. F. Hinton and P. Pulay, J. Am. Chem. Soc., 1990, 112, 8251-8260.

G. Schreckenbach and T. Ziegler, J. Phys. Chem., 1995, 99, 606-611.

S. K. Wolff, T. Ziegler, E. van Lenthe and E. J. Baerends, J. Chem. Phys., 1999, 110, 7689.

M. Kaupp, M. Bühl and V. G. Malkin, Calculation of NMR and EPR parameters: theory and applications, John Wiley \& Sons, Inc., 2006.

F. Furche, R. Ahlrichs, C. Hättig, W. Klopper, M. Sierka and

F. Weigend, Wiley Interdiscip. Rev. Comput. Mol. Sci., 2014, 4, 91-100.

A. Schäfer, C. Huber and R. Ahlrichs, J. Chem. Phys., 1994, 100, 5829.

F. Weigend and R. Ahlrichs, Phys. Chem. Chem. Phys., 2005, 7, 3297-305.

K. Eichkorn, O. Treutler, H. Öhm, M. Häser and R. Ahlrichs, Chem. Phys. Lett., 1995, 240, 283-290.

D. Sundholm, R. J. F. Berger and H. Fliegl, Phys. Chem. Chem. Phys., 2016, 18, 15934-15942.

A. R. Katritzky, P. Barczynski, G. Musumarra, D. Pisano and M. Szafran, J. Am. Chem. Soc., 1989, 111, 7-15. K. Jug and A. M. Köster, J. Phys. Org. Chem., 1991, 4, 163169.

C. W. Bird, Tetrahedron, 1996, 52, 9945-9952.

A. R. Katritzky, K. Jug and D. C. Oniciu, Chem. Rev., 2001, 101, 1421-1450. 
2012, 116, 9421-9430.

69 S. Fias, S. Van Damme and P. Bultinck, J. Comput. Chem., 2008, 29, 358-366.

70 P. Lazzeretti, Phys. Chem. Chem. Phys., 2004, 6, 217-223.

71 P. von R. Schleyer, C. Maerker, A. Dransfeld, H. Jiao and N. J. R. van E. Hommes, J. Am. Chem. Soc., 1996, 118, 63176318.

72 Z. Chen, C. S. Wannere, C. Corminboeuf, R. Puchta and P. von R. Schleyer, Chem. Rev., 2005, 105, 3842-3888.

73 M. Solà, F. Feixas, J. O. C. Jiménez-Halla, E. Matito and J. Poater, Symmetry (Basel)., 2010, 2, 1156-1179.

74 J. A. Pople and K. G. Untch, J. Am. Chem. Soc., 1966, 88, 4811-4815.

75 P. R. von Schleyer and H. Jiao, Pure Appl. Chem., 1996, 68, 209-218.

76 L. Noodleman and E. R. Davidson, Chem. Phys., 1986, 109, 131-143.

77 L. Noodleman and D. A. Case, 1992, pp. 423-470.

78 L. Noodleman, J. Chem. Phys., 1981, 74, 5737-5743.

79 K. Morokuma, J. Chem. Phys., 1971, 55, 1236-1244.

80 G. Te Velde, F. M. Bickelhaupt, E. J. Baerends, C. Fonseca Guerra, S. J. a. van Gisbergen, J. G. Snijders and T. Ziegler, J. Comput. Chem., 2001, 22, 931-967.

81 T. Ziegler and A. Rauk, Theor. Chim. Acta, 1977, 46, 1-10.

82 S. F. Boys and F. Bernardi, Mol. Phys., 1970, 19, 553-566.

83 R. F. Nalewajski, J. Mrozek and A. Michalak, Int. J.

Quantum Chem., 1997, 61, 589-601.

84 A. Michalak, R. L. DeKock and T. Ziegler, J. Phys. Chem. A, 2008, 112, 7256-7263.

85 G. Frenking and S. Shaik, Eds., The Chemical Bond: Fundamental Aspects of Chemical Bonding, Wiley-VCH Verlag GmbH \& Co. KGaA, Weinheim, Germany, 2014.

86 H. Fliegl, D. Sundholm, S. Taubert, J. Jusélius and W. Klopper, J. Phys. Chem. A, 2009, 113, 8668-8676.

87 T. Heine, C. Corminboeuf and G. Seifert, Chem. Rev., 2005, 105, 3889-3910.

88 R. Islas, T. Heine and G. Merino, Acc. Chem. Res., 2012, 45, 215-28.

89 G. Merino, T. Heine and G. Seifert, Chemistry, 2004, 10, 4367-71.

90 E. Kleinpeter, S. Krüger and A. Koch, J. Phys. Chem. A, 2015, 119, 4268-76.

91 S. Klod and E. Kleinpeter, J. Chem. Soc. Perkin Trans. 2, 2001, 1893-1898.

92 E. Kleinpeter, A. Koch and P. R. Seidl, J. Phys. Chem. A, 2008, 112, 4989-95.

93 A. C. Tsipis, Phys. Chem. Chem. Phys., 2009, 11, 8244.

94 D. Du, D. Sundholm and H. Fliegl, J. Chinese Chem. Soc., 2016, 63, 93-100.

95 G. Monaco and R. Zanasi, J. Phys. Chem. A, 2014, 118, 1673-1683.

96 A. Stanger, J. Org. Chem., 2006, 71, 883-893. 